\title{
MITIGATION OF HARMONIC DISTORTION BY POWER ELECTRONIC INTERFACE CONNECTING DISTRIBUTED GENERATION SOURCES TO A WEAK GRID
}

\author{
R. M. Moreno, J. A. Pomilio, L. C. Pereira da Silva and S. P. Pimentel* \\ School of Electrical and Computer Engineering - University of Campinas, Campinas, Brazil \\ *Federal Institute of Education, Science and Technology of Goiás, Itumbiara, Brazil \\ rodomore@dsce.fee.unicamp.br, antenor@dsce.fee.unicamp.br, lui@dsee.fee.unicamp.br, sergio@dsce.fee.unicamp.br
}

\begin{abstract}
In this paper a Power Electronic Interface (PEI) that integrates up to two renewable energy sources is presented. The power flow of the different distributed sources is controlled through the DC link and the AC terminal voltage of the voltage source converter (VSC) adjustment. The local sources can be controlled to supply electricity to the local load and export the exceeding energy to the grid. The system is analyzed under distorted grid voltage in order to discuss the effectiveness of different compensation strategies. Solutions based on resonant passive filters and on the injection of harmonics to compensate the voltage grid distortion are presented .
\end{abstract}

Keywords - Harmonic compensation, power electronic interface, renewable energy source, resonant passive filter, voltage source converter.

\section{INTRODUCTION}

The conceptual and technological challenges associated with Distributed Generation (DG) systems have been deeply studied in recent years. Their main characteristics, such as the reduction of power demand from the grid, the backup power function, the possibilities of improving the power quality, and ancillary services to the power grid are impelling the development of associated technologies, making possible to connect such power sources to the utility grid [1-3].

Due to the characteristics of many of the distributed sources, as solar panels, fuel cells, asynchronous generators, it is necessary a power electronics interface (PEI) for adequately conditioning the electric power to connect the DG with the grid. The PEI can be controlled to perform many functions, such as controlling the power flow, regulating the local voltage, harmonics compensation, etc.

It is quite common to find cases in which the DG source is connected to a weak grid. Such grids typically present power quality problems due to the low short-circuit level and harmonic distortion produced by non-linear loads, among others problems [4-5].

One important issue in this subject is how to deal with islanding situation [6-8]. As the DG has stand-alone [9-10] capability, instead of simply disconnecting it from the grid and turn it off, it could be of interest to use it to feed the local load.

\footnotetext{
Manuscript received on 05/10/2009. Revised on 18/11/2009. Accepted by recommendation of the Editor Fernando L. M. Antunes.
}

This paper presents a DG system with AC and DC sources which are connected to the grid by a power electronic interface, as shows figure 1.

In this scheme, the induction generator (IG) is directly connected to the grid. At the Point of the Common Coupling (PCC), a voltage source converter (VSC) serves as the interface of the DC source, but it is also responsible for controlling the power exchange with the grid, regulating and balancing the PCC voltage, and filtering load current harmonics.

The VSC is controlled as an ideal AC voltage source with sinusoidal waveform, constant frequency and amplitude. The VSC is controlled to keep constant the DC link voltage, which guarantees the power balance among the local power sources, the local load and the grid [11-14]. In the proposed structure, batteries could be used to supply energy to the local load in the period of low or no power generation from the local source. This situation was studied by simulation in [11] with sinusoidal grid voltage.

The objective of this paper is to evaluate the overall system operation when the grid voltage present harmonics distortion, and the consequent problems, even if the distortion is low enough to comply with specific standards [15].

\section{CONTROL STRATEGIES}

In grid-connected mode, the main control rule of the PEI regards the active power control, which controls the power flow, injecting or absorbing the excess or deficit of power produced by the local source. The active power balance of the system is given by:

$$
\begin{gathered}
P_{S}=P_{I G}-P_{\text {Load }} \\
P_{S}=\frac{V C \cdot V S}{X_{L s}} \cdot \sin \beta
\end{gathered}
$$

$\mathrm{P}_{\mathrm{S}}$ is the grid active power, $\mathrm{P}_{\mathrm{IG}}$ is the active power generated by the IG and DC power source, and $\mathrm{P}_{\text {Load }}$ is the active power consumed by the local load. $\beta$ is the angle between $V_{C}$ and $\mathrm{V}_{\mathrm{S}}$. The power balance is obtained by the power angle $(\beta)$ regulation that controls the active power flow to the grid, $\mathrm{P}_{S}$, according to (2). $\mathrm{V}_{\mathrm{C}}$ is the voltage at the local load terminals, $\mathrm{V}_{\mathrm{S}}$ is the voltage of the grid, $\mathrm{X}_{\mathrm{Ls}}$ is the coupling reactance with the grid. 


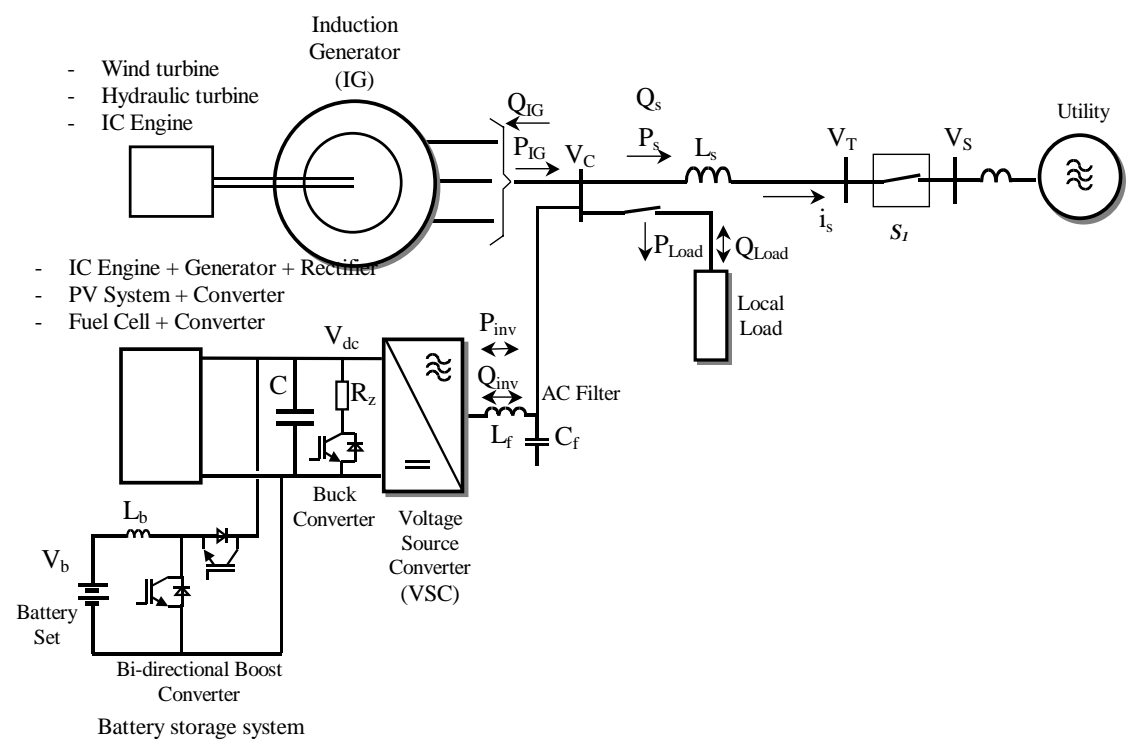

Fig. 1. Power Electronic Interface system

As show in $[11,14]$, any variation of the power balance introduces $V_{\mathrm{dc}}$ voltage variation. A PI controller, shown in figure 2 , regulates the angle $\beta$ to reestablish the active power balance and to adjust the DC voltage to the set point. The second external control loop of the PEI assures the operation at unity power factor, as also shown in figure 2. From (3), for balancing the reactive power, the amplitude of the voltage $V_{C}$ is adjusted according to (4) to get $\mathrm{Q}_{\mathrm{s}}=0$.

$$
\begin{gathered}
Q_{S}=Q_{\text {Load }}-\left(Q_{i n v}-Q_{I G}\right) \\
Q_{S}=\frac{V_{C}^{2}}{X_{L s}}-\frac{V_{C} \cdot V_{S}}{X_{L s}} \cdot \cos \beta
\end{gathered}
$$

$\mathrm{Q}_{\mathrm{s}}$ is the reactive power of the grid, $\mathrm{Q}_{\mathrm{Load}}$ is the reactive power consumed by the local load, $\mathrm{Q}_{\mathrm{IG}}$ is the reactive power consumed by the IG and $Q_{\text {inv }}$ is the reactive power of the VSC. These two external reference signals $\left(\mathrm{V}_{\mathrm{c}, \mathrm{ref}}\right.$ and $\left.\beta_{\mathrm{ref}}\right)$ represent the local voltage vector, expressed in polar form. This reference signal is transformed to rectangular form and after to alfa-beta reference frame using the angular position $\theta$ of the voltage grid calculated by the PLL system [11,20-22]. These two references $\left(\mathrm{V}_{\mathrm{c} 1 \alpha, \text { ref }}, \mathrm{V}_{\mathrm{c} 1 \beta \mathrm{ref}}\right)$ are the input of the VSC controller, as shows figure 3 . The voltage controller uses a Proportional plus Resonant $(\mathrm{P}+\mathrm{R})$ controller and a harmonic compensator (HC) for selective compensating of low-order voltage harmonics [16-19]. The transfer functions are shown in (5) and (6) for the fundamental and harmonic components respectively.

$$
\begin{gathered}
G_{P R}(s)=k_{p}+\frac{2 k_{i 1} w_{b 1} s}{s^{2}+2 w_{b 1} s+w^{2}} \\
G_{h}(s)=\frac{2 k_{i h} w_{b h} s}{s^{2}+2 w_{b h} s+(h w)^{2}}
\end{gathered}
$$

Where: $k_{p}$ is the proportional gain, $h$ is the harmonic order, $\mathrm{k}_{\mathrm{ih}}$ represents the individual resonant gain, $\mathrm{w}_{\mathrm{bh}}$ is the bandwidth around the resonant frequency, and $\mathrm{w}$ is the fundamental frequency.

The output controllers $(\mathrm{P}+\mathrm{R}$ and $\mathrm{HC})$ are the references for the internal current control loop for faster dynamic

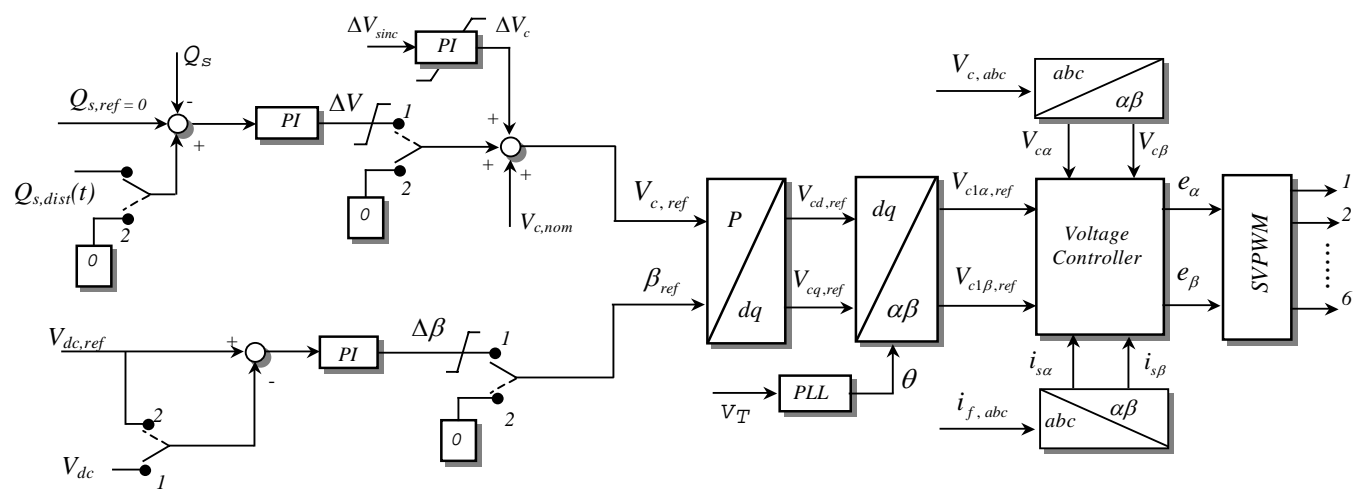

Fig. 2. Block diagram control of the Power Electronic Interface 


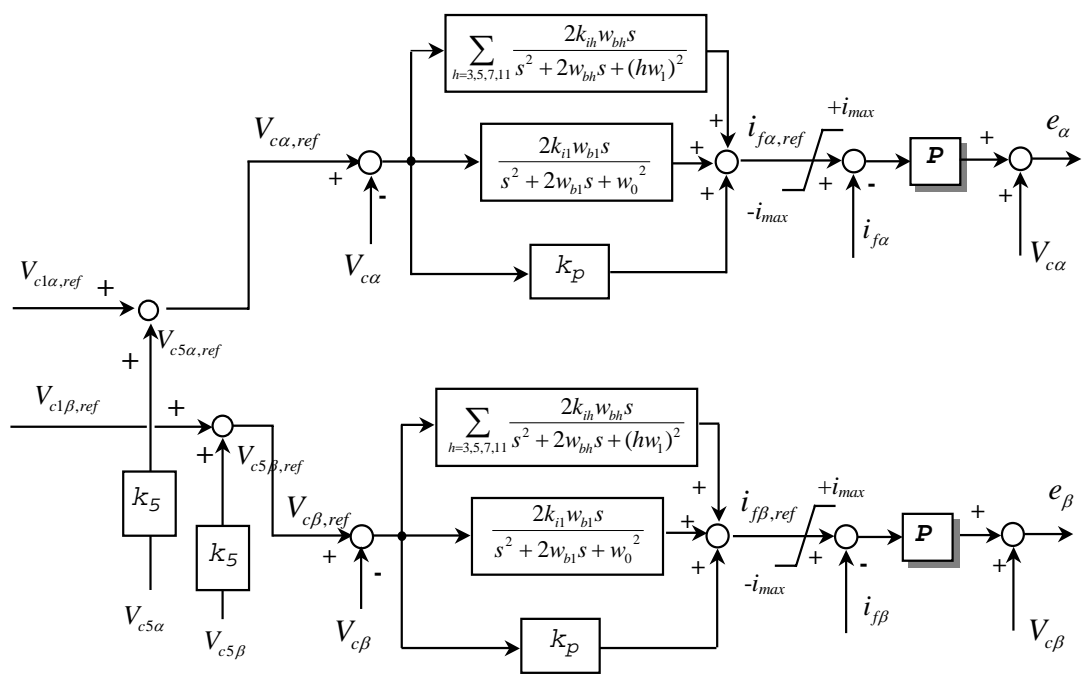

Fig. 3. Voltage controller scheme of the VSC

response. The outputs of this controller are the reference voltages $\left(\mathrm{e}_{\alpha}, \mathrm{e}_{\beta}\right)$ for the space vector modulator that generates the command pulses for the VSC.

The VSC automatically compensates for the harmonics and the reactive power of the load by imposing sinusoidal voltage waveform on the local load bus. This means that no harmonics will flow through the grid and the IG (both supposed sinusoidal).

In the autonomous operation, when the interface is not connected to the grid, the control of the VCS changes strategy to keep the amplitude and frequency of the local voltage constant. This is obtained by changing the position of the switch in the Figure 2 from position 1 to 2 [9-10]. Without the grid voltage, the DC bus voltage is no longer controlled by the power angle $\beta$. Instead, the buck and the boost converters take the control of the DC bus voltage [11].

Simulation results are shown for the parameters of the PEI and the system in the Tables V, VI and VII in the appendix. In this case, the local load is a three-phase rectifier of 2.0 $\mathrm{kW}$, the IG injects $0.87 \mathrm{~kW}$ and the active power absorbed from the grid is $1.13 \mathrm{~kW}$. The grid voltage is supposed sinusoidal.

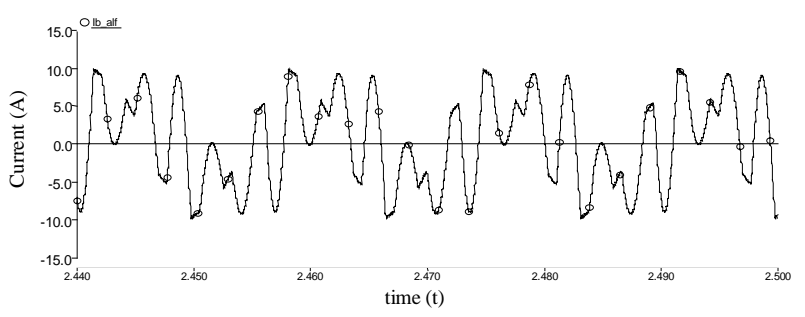

Fig. 4. Inductor current of the LC filter ( $\left.\mathrm{i}_{\mathrm{Lf}}\right)$

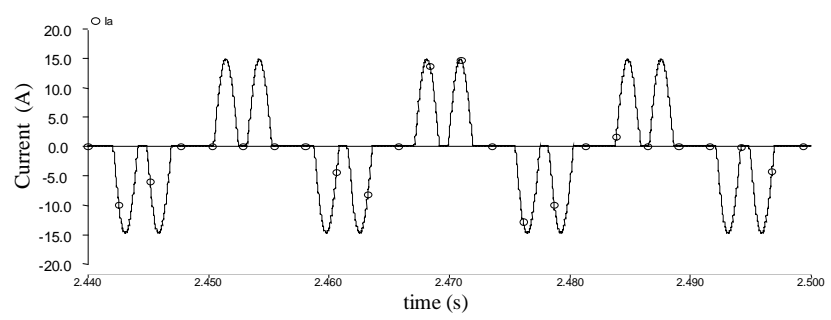

Fig. 5. Local load current ( $\left.\mathrm{i}_{\text {Load }}\right)$

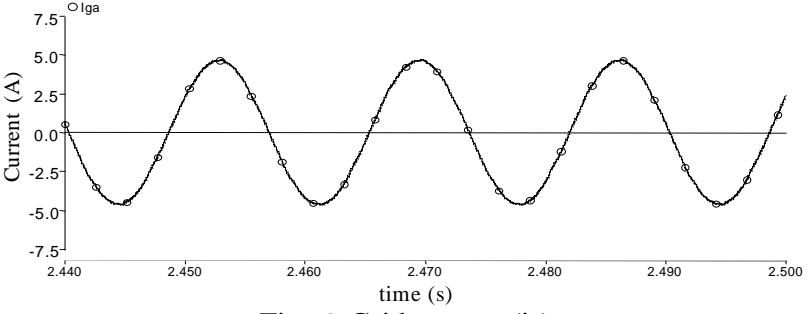

Fig. 6. Grid current $\left(i_{s}\right)$

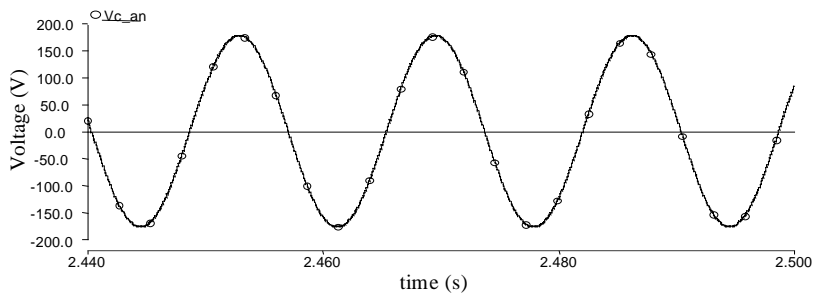

Fig. 7. Local voltage (Vc)

Figure 4 shows the filtered current of the VSC. As can be seen, all the distorted current of the local load is absorbed by the VSC due to the $\mathrm{P}+\mathrm{R}$ and $\mathrm{HC}$ control that imposes a sinusoidal PCC voltage. The current of the local load is shown in figure 5. Figure 6 shows the current absorbed from the grid, resulting unitary power factor. The local voltage is show in figure 7.

\section{POWER QUALITY}

The performance of the PEI is now analyzed when the grid voltage is distorted (5\% of fifth harmonic). The grid voltage is show in figure 8.

Figure 9 displays the local voltage with sinusoidal waveform achieved by the P+R and HC controller, indicating the excellent response of the controller to guarantee the local voltage quality. 


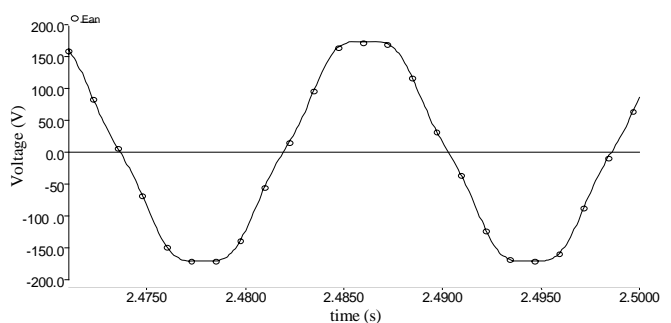

Fig. 8. Voltage of the grid $\left(\mathrm{V}_{\mathrm{S}}\right)$

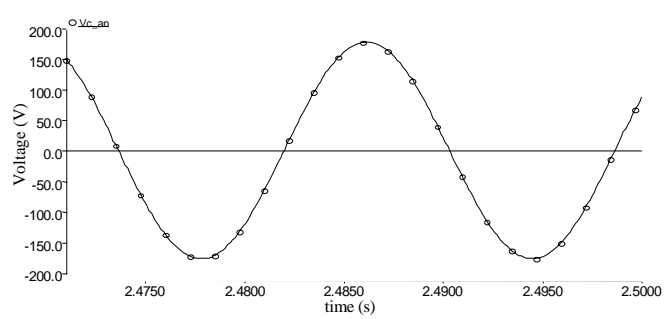

Fig. 9. Local voltage $\left(\mathrm{V}_{\mathrm{C}}\right)$

Figure 10 shows the resulting line current with the distorted grid voltage. In this simulation, the IG does not inject active power $\left(\mathrm{P}_{\mathrm{IG}}=0\right)$ and the local load $\left(\mathrm{P}_{\text {load }}=2 \mathrm{~kW}\right)$ is fed only by the grid. The coupling inductance and the feeder impedance are the only elements that limit the harmonic current.

Increasing the coupling inductance is not a solution for reducing the current harmonic. Its value must be low enough in order to allow the power flow control while maintaining an acceptable local voltage regulation.

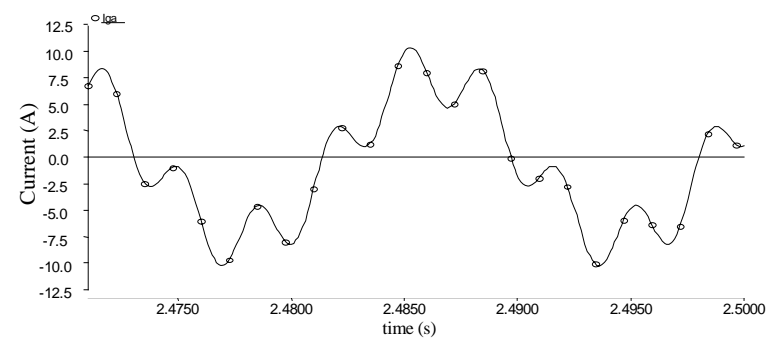

Fig. 10. Current of the grid ( $\left.\mathrm{i}_{\mathrm{S}}\right)$

A. Compensation by series connected resonant filter

There are some alternatives for reducing the current distortion. One of the options is connecting a passive resonant series filter. Such filter is obtained by connecting a capacitor in parallel with the coupling inductor, to present high impedance on the harmonic frequency, as shows the figure 11. The value of the capacitor is calculated for parallel resonance on the desired harmonic present in the voltage grid [4-5].

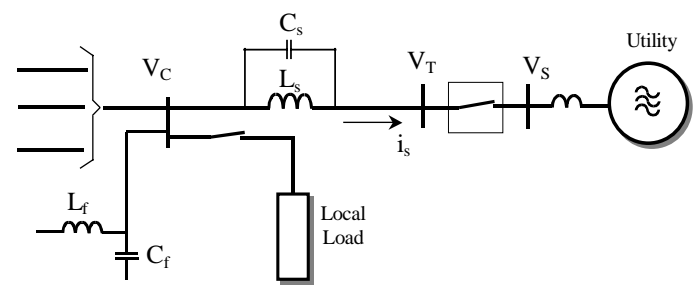

Fig. 11. Parallel resonant filter LC
The resonant frequency is calculated by (7). Q is the quality factor (8).

$$
\begin{gathered}
f_{r}=\frac{1}{2 \pi \sqrt{L_{s} C_{s}}} \sqrt{1-\frac{C_{s} R_{s}^{2}}{L_{s}}} \\
Q=\frac{w_{r} L_{s}}{R_{s}}
\end{gathered}
$$

Where:

$$
\begin{array}{ll}
f_{r} & \text { - Resonant frequency. } \\
w_{r} & \text { - Angular frequency }\left(w_{r}=2 \pi f_{r}\right) . \\
L_{s} & \text { - Coupling inductor. } \\
R_{s} & \text { - Resistance of the coupling inductor. } \\
C_{s} & \text { - Parallel capacitor. } \\
\mathrm{Q} & \text { - Quality factor of the coupling inductor. }
\end{array}
$$

When the inductor value and the resonant frequency are known, the capacitor may be calculated by (9)

$$
C_{s}=\frac{1}{\left(w_{r}^{2} \cdot L_{s}+\frac{R_{s}^{2}}{L_{s}}\right)}
$$

Table I show the different capacitor values calculated for different quality factor “Q”, given the inductor Ls.

TABLE I

Capacitance for different $\mathbf{Q}$

\begin{tabular}{ccc}
\hline \multicolumn{3}{c}{ Ls $=0.75 \mathrm{mH}, \mathrm{f}_{\mathrm{r}}=300 \mathrm{~Hz}$} \\
\hline $\mathrm{Q}$ & $\mathrm{Rs}(\mathrm{ohm})$ & $\mathrm{Cs}(\mu \mathrm{F})$ \\
\hline 10 & 0.1414 & 371.54 \\
\hline 30 & 0.0471 & 374.84 \\
\hline 50 & 0.0283 & 375.11 \\
\hline
\end{tabular}

Simulation results are show in figures 12 and 13 for threephase resistive local load of $2.0 \mathrm{~kW}$ in two situations: for the power generated by the IG, $\mathrm{P}_{\mathrm{IG}}=0$ and $\mathrm{P}_{\mathrm{IG}}=1.3 \mathrm{~kW}$ (power injected by the IG) and quality factor $\mathrm{Q}=10$.

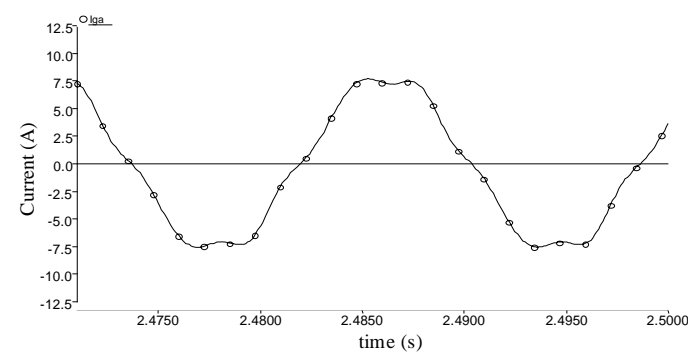

Fig. 12. Current of the grid ( $\left.\mathrm{i}_{\mathrm{S}}\right)$ when $\mathrm{P}_{\mathrm{IG}}=0, \mathrm{Q}=10$

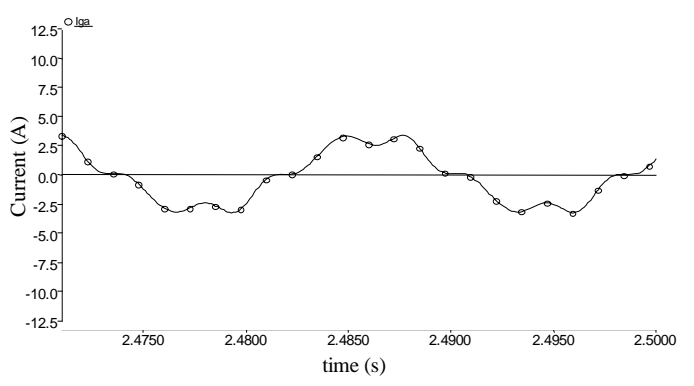

Fig. 13. Current of the grid $\left(\mathrm{i}_{\mathrm{S}}\right)$ when $\mathrm{P}_{\mathrm{IG}}=1.3 \mathrm{~kW}, \mathrm{Q}=10$ 
The current THD varies with the active power injected by the IG because the fundamental component changes. This is an arithmetic effect. The important variable is the absolute value of the harmonic current that remains constant, as shown in Table II.

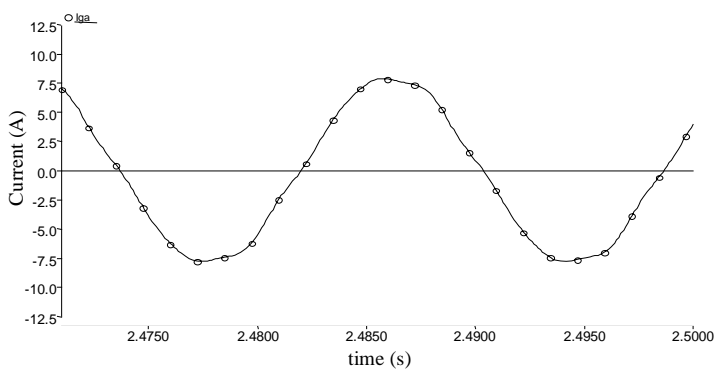

Fig. 14. Current of the grid ( $\mathrm{i}_{\mathrm{S}}$ ) when $\mathrm{P}_{\mathrm{IG}}=0, \mathrm{Q}=30$

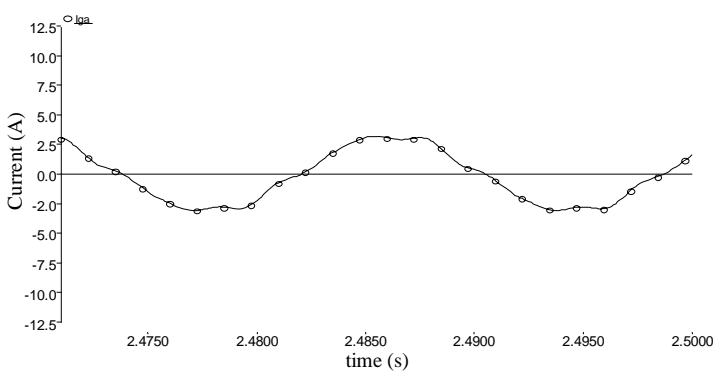

Fig. 15. Current of the grid $\left(\mathrm{i}_{\mathrm{S}}\right)$ when $\mathrm{P}_{\mathrm{IG}}=1.3 \mathrm{~kW}, \mathrm{Q}=30$

Figures 14 and 15 show the results for quality factor $\mathrm{Q}=$ 30. The higher the $Q$ value, more effective is the filtering.

Additional parallel resonant filters should be connected in series with the line if others harmonics in the voltage grid are detected. However, the total series inductance should not be higher than a maximum value in order to allow the desired local voltage regulation, as explained before.

TABLE II

Current harmonics for different passive filters and IG power

\begin{tabular}{cccccc}
\hline \multicolumn{6}{c}{ P-Load = 2.0 kW, THD- $\mathrm{V}_{\mathrm{s}}=4.8 \%$} \\
\hline $\mathrm{Q}$ & $\begin{array}{c}\mathrm{P}_{\mathrm{IG}} \\
(\mathrm{kW})\end{array}$ & $\begin{array}{c}\mathrm{P}_{\text {grid }} \\
(\mathrm{kW})\end{array}$ & $\begin{array}{c}\text { THD-i }_{\mathrm{s}} \\
(\%)\end{array}$ & $\begin{array}{c}\mathrm{I}_{\mathrm{s} 5} \\
(\mathrm{r} . \mathrm{m} . \mathrm{s})\end{array}$ & $\begin{array}{c}\mathrm{I}_{\mathrm{s} 1} \\
(\mathrm{r} . \mathrm{m} . \mathrm{s})\end{array}$ \\
\hline 10 & 1.83 & 0.17 & 63.43 & 0.439 & 0.729 \\
\hline & 0.8 & 1.2 & 12.7 & 0.439 & 3.348 \\
\hline 30 & 1.83 & 0.17 & 25.7 & 0.162 & 0.729 \\
\hline & 0.8 & 1.2 & 5.1 & 0.162 & 3.348 \\
\hline 50 & 1.83 & 0.17 & 19.1 & 0.104 & 0.729 \\
\hline & 0.8 & 1.2 & 3.8 & 0.104 & 3.348 \\
\hline
\end{tabular}

\section{B. Compensation by local voltage distortion}

The limitation of the grid current harmonics by the local voltage control is investigated. The idea is to include in the voltage reference of the VSC (figure 3) some harmonic signals. Voltage harmonics with the same frequency, phase and amplitude of the grid voltage harmonic will be added to the fundamental component of local voltage $\mathrm{V}_{\mathrm{C}}$, looking for reducing the flow of the harmonic current between the grid and the PEI, while maintaining an acceptable local voltage distortion.

To generate these compensation signals, resonant filters with transference function as expressed in (10) are used in the control structure.

$$
G(s)=\frac{K_{f} w_{c}\left(s+w_{c}\right)}{s^{2}+2 w_{c} s+w_{c}{ }^{2}+w_{n}{ }^{2}}
$$

Where:

$$
\begin{aligned}
& K_{f} \text { - Filter gain. } \\
& w_{n} \text { - Frequency of the selected harmonic in rad/s. } \\
& w_{c}-\text { Band frequency in rad/s to improved the transient } \\
& \text { performance of the filter }
\end{aligned}
$$

The filters detect the voltage harmonics present in each phase of the grid $\left(\mathrm{V}_{\mathrm{s}, \mathrm{an}}, \mathrm{V}_{\mathrm{s}, \mathrm{bn}}\right.$ and $\left.\mathrm{V}_{\mathrm{s}, \mathrm{cn}}\right)$. The figure 16 shows the detection scheme where three resonant filters for the fifth harmonic are employed.

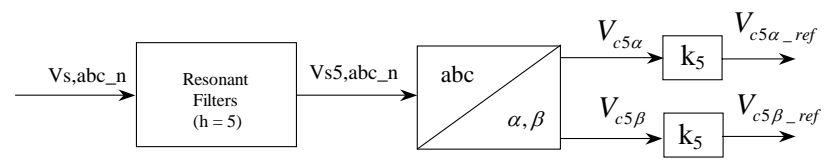

Fig. 16. Voltage harmonic detector

After the three-phase voltages harmonics have been detected, they are transformed to the alfa-beta reference frame by (11).

$$
\left[\begin{array}{l}
V_{c 5 \alpha} \\
V_{c 5 \beta}
\end{array}\right]=\frac{2}{3}\left[\begin{array}{rrr}
1 & -\frac{1}{2} & -\frac{1}{2} \\
0 & -\frac{\sqrt{3}}{2} & \frac{\sqrt{3}}{2}
\end{array}\right] \cdot\left[\begin{array}{l}
V_{s 5, a n} \\
V_{s 5, b n} \\
V_{s 5, c n}
\end{array}\right]
$$

Where:

$$
\begin{aligned}
& \mathrm{V}_{\mathrm{s} 5 \text {,an }}, \mathrm{V}_{\mathrm{s} 5, \mathrm{bn}} \text { and } \mathrm{V}_{\mathrm{s5}, \mathrm{cn}} \text { - Are the fifth voltage harmonics of } \\
& \text { each phase. } \\
& V_{c 5 \alpha}, V_{c 5 \beta} \text { - Are the output signals. }
\end{aligned}
$$

The two-output signals $\left(V_{c 5 \alpha}, V_{c 5 \beta}\right)$ are affected by a gain factor $\left(k_{5}\right)$ in (12). These compensations signals are added to the alfa and beta voltage reference as show the Figure 3.

$$
\left[\begin{array}{l}
V_{c 5 \alpha_{-} r e f} \\
V_{c 5 \beta_{-} r e f}
\end{array}\right]=k_{5} \cdot\left[\begin{array}{c}
V_{c 5 \alpha} \\
V_{c 5 \beta}
\end{array}\right]
$$

The factor $k_{5}$ is selected between 0.0 and 1.0 looking for reducing the grid current distortion while keeping the distortion of the local voltage bellow the desired limit, complying with the standards and not affecting the operation of the local load.

$$
I_{s 5}=\frac{V_{s 5}\left(1-k_{5}\right)}{5 w\left(L_{S}+L_{T}\right)}
$$

Where:

$V_{s 5}$ - Fifth harmonic component of the phase voltage grid

$L_{T}$ - Leakage Inductance of the transformer.

$L_{s}$ - Coupling inductor 
From the equivalent circuit and (14), when the $\mathrm{k}_{5}$ factor value tends to one, the current harmonic amplitude reduces.

Simulation results are shown in Table III for different compensation factor $k_{5}$ and power injected by the IG. Figure 17 shows the per phase equivalent circuit.

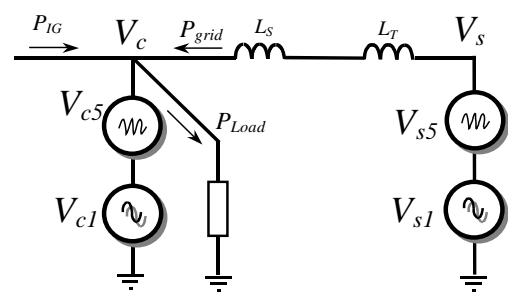

Fig. 17. Equivalent circuit of the power interface connected to the grid

TABLE III

Harmonic current attenuation for different local voltage harmonic compensation

\begin{tabular}{ccccccc}
\hline \multicolumn{7}{c}{ P_Load $=2.0 \mathrm{~kW}$, THD_V } \\
\hline $\mathrm{k}_{5}$ & $\begin{array}{c}\mathrm{P}_{\mathrm{IG}} \\
(\mathrm{kW})\end{array}$ & $\begin{array}{c}\mathrm{P}_{\text {grid }} \\
(\mathrm{kW})\end{array}$ & $\begin{array}{c}\text { THD-i } \\
(\%)\end{array}$ & $\begin{array}{c}\text { THD-V } \\
(\%)\end{array}$ & $\begin{array}{c}\mathrm{I}_{\mathrm{s} 5} \\
(\mathrm{r} . \mathrm{m} . \mathrm{s})\end{array}$ & $\begin{array}{c}\mathrm{I}_{\mathrm{s} 1} \\
(\mathrm{r} . \mathrm{m} . \mathrm{s})\end{array}$ \\
\hline 1.0 & 1.8 & 0.2 & 3.6 & 4.88 & 0.019 & 0.673 \\
\hline & 0.8 & 1.2 & 0.72 & 4.85 & 0.019 & 3.28 \\
\hline 0.95 & 1.8 & 0.2 & 16.3 & 4.6 & 0.108 & 0.664 \\
\hline & 0.8 & 1.2 & 3.3 & 4.6 & 0.107 & 3.277 \\
\hline 0.8 & 1.8 & 0.2 & 62.9 & 3.8 & 0.418 & 0.664 \\
\hline & 0.8 & 1.2 & 12.7 & 3.8 & 0.417 & 3.270 \\
\hline \multicolumn{7}{c}{} \\
& & & & &
\end{tabular}

From the results in Table III, an almost complete reduction in the grid current harmonic is achieved when the same voltage grid distortion is produced by the VSC in the local voltage. When the factor $\mathrm{k}_{5}$ decreases, reducing the local voltage distortion, the current harmonic attenuation decreases.

Another consequence of the local voltage distortion is the presence of harmonic current in the induction generator and the resulting torque oscillation.

\section{Compensation by series resonant filter and voltage distortion}

The system behavior was verified employing the resonant filter plus the voltage compensation, as shown in the equivalent circuit of figure 18. In this case, the denominator of (14) tends to a higher value at the resonance, minimizing the harmonic, even if the filter quality factor is not so high.

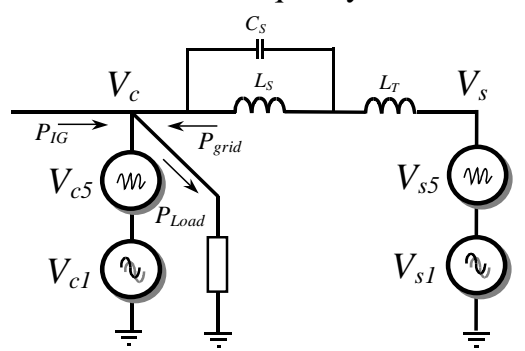

Fig. 18. Equivalent circuit of the power interface with resonant passive filter.

Reducing the difference between the amplitude of the harmonic voltage in the grid and the in the PCC will reduce the grid current harmonic. The higher the series impedance (due to the resonant parallel LC passive filter), the lower the current grid distortion.

The combination of these two methods makes the current distortion achieve an acceptable value and, at the same time, the local voltage distortion can comply with the standards.

The next results correspond to $\mathrm{P}_{\mathrm{IG}}=1.8 \mathrm{~kW}$. Figure 19 shows the grid current waveform, figure 20 displays the waveform of the local voltage and the figures 21 and 22 show respectively the current and the electromagnetic torque in the induction generator. As expected, the PCC voltage distortion affects the IG operation.

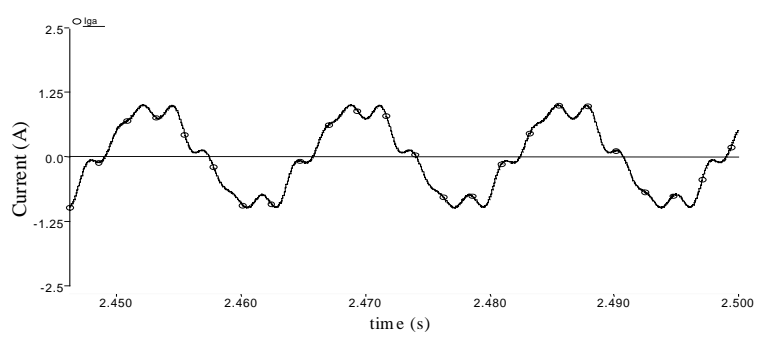

Fig. 19. Grid current (is)

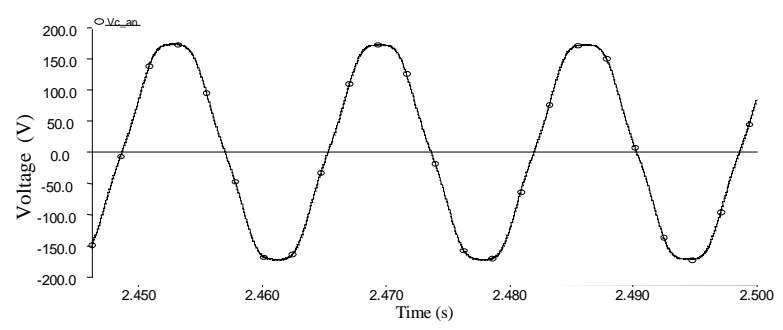

Fig. 20. Local voltage $\left(\mathrm{V}_{\mathrm{C}}\right)$

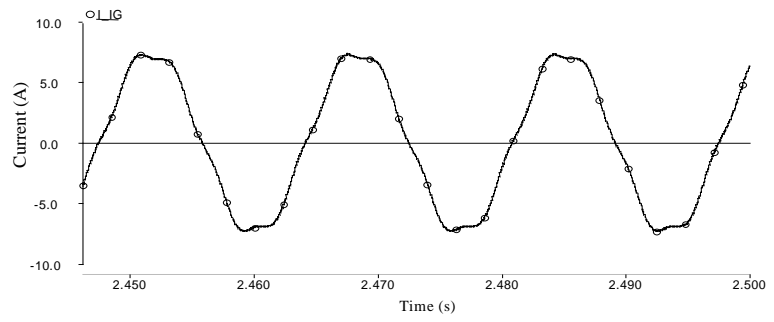

Fig. 21. Induction Generator current ( $\left.\mathrm{i}_{\mathrm{IG}}\right)$

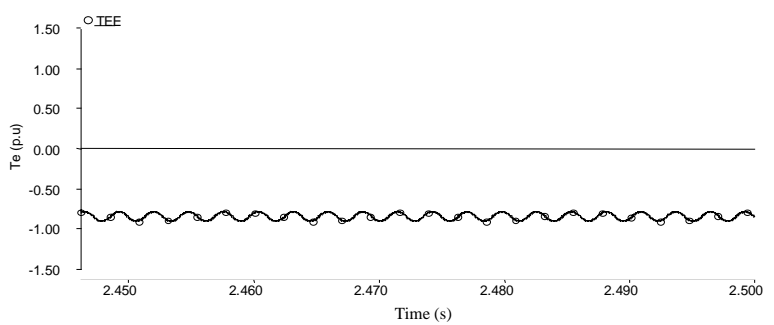

Fig. 22. Electromagnetic Torque Te (p.u.). $\mathrm{T}_{\text {base }}=11.6 \mathrm{Nm}$

\section{CONCLUSION}

This paper has investigated the operation of a distributed generation system, connected to the grid using a power electronic interface, under non-ideal power quality conditions. More specifically, it has been investigated the effects of voltage distortion in the DG currents. The DG system comprises an induction generator, directly connected 
to the grid, and a DC source, connected through a voltage source converter.

The VSC is controlled as a voltage source and regulates the power exchange among the various supplies, while guarantees the local voltage quality.

In case of grid voltage distortion, as the VSC assures sinusoidal PCC voltage, a high harmonic current flows from the mains to the DG system, limited by the impedance of the series link inductor.

The connection of a capacitor in parallel with this inductor produces a resonant filter that can reduce the current distortion. The effectiveness of this solution depends on the quality factor of the inductor. Additional resonant filters should be connected for each harmonic voltage. In this case, the series inductance must be split. This solution does not affect the quality of the local voltage.

The compensation method that reproduces in the local voltage the same distortion (harmonics) present in the grid voltage is a more practical solution from the point of view of implementation, since it only needs an additional controller. The inconvenience of this method is the distortion introduced in the local voltage that, depending on the value, may affect the local load operation. This effect is clear for the induction generator, producing current distortion and electromagnetic torque oscillation.

The compensation scheme using both methods opens the possibility of using a resonant filter with low quality factor while maintaining an acceptable local voltage quality, thus reducing the IG torque fluctuation.

\section{ACKNOWLEDGMENTS}

The authors would like to thank the Brazilian agencies FAPESP (Fundação de Amparo à Pesquisa do Estado de São Paulo), CNPq and CAPES by the financial support, and Texas Instruments for the technical support.

\section{REFERENCES}

[1] A. Barin, L. F. Pozzatti, R. Q. Machado, L. N. Canha, F. A. Farret, A. da R. Abaide, Multicriteria Analysis of Impacts of Distributed Generation Sources on Operational Network Characteristics for Distribution System Planning Concerning Steady-state and Transient Operations, Eletrônica de Potência, Vol. 14 -No.2, May 2009, pp.75-83.

[2] J. M. Carrasco, L. G. Franquelo, J. T. Bialasiewiciz, E. Galván, R. C. Portillo Guisado, M. Á. M. Prats, J. I. León, N. Moreno-Alfonso, Power-Electronics Systems for the Grid Integration of Renewable Energy Source: A Survey, IEEE Transaction on Industry Electronics, Vol. 53, No. 4, August 2006, pp. $1002-1016$.

[3] F. Blaabjerg, R. Teodorescu, M. Liserre and A. V. Timbus, Overview of Control and Grid Synchronization for Distributed Power Generation Systems, IEEE Transaction on Industrial Electronics, Vol. 53, No. 5, October 2006, pp. 1398-1409.

[4] J-S. Lai and T. S. Key, Effectiveness of Harmonics Mitigation Equipment for Commercial Office buildings,
IEEE Transaction on Industry Applications, vol.33, No. 4, July/August 1997, pp. 1104-1110

[5] F. Z. Peng, Harmonic Source and Filtering Approaches, IEEE Industry Applications Magazine, July/August 2001, pp. 18-25.

[6] Z. Ye, R. Walling, L. Garces, R. Zhou, L. Li, and T. Wang, Study and Development of Anti Islanding Control for Grid-Connected Inverters, National Renewable Energy Laboratory (NREL/SR - 560-36243), May 2004.

[7] G. Hernandez-Gonzalez, R. Iravani, Current Injection for Active Islanding Detection of ElectronicallyInterfaced Distributed Resources, IEEE Transaction on Power Delivery, vol. 21, No. 3, July 2006, pp. 16981705.

[8] Z. Ye, A. Kolwalkar, Y. Zhang, P. Du, R. Walling, Evaluation of Anti-Islanding Schemes Base on No detection Zone Concept, IEEE Transactions on Power Electronics, vol. 19, No. 5, September 2004, pp. 11711176.

[9] R. Teodorescu, and F. Blaabjerg, Flexible Control of Small Wind Turbines With Grid Failure Detection Operating in Stand-Alone and Grid-Connected Mode, IEEE Transactions on Power Electronics, vol. 19, No. 5, September 2004, pp. 1323-1332.

[10] Y. Li, D. M. Vilathgamuwa and P. C. Loh, "Design, Analysis, and Real-Time Testing of a Controller for Multibus Microgrid System”, IEEE Transactions on power electronics, vol. 19, No. 5, September 2004, pp. 1195-1203.

[11] R. M. Martinez, J. A. Pomilio and L. C. Pereira da Silva, Power Flow Control and Islanding Detection of a Local Generation System with Induction Generator, Proceedings of the $34^{\text {th }}$ Annual Conference of IEEE Industrial Electronics Society - IECON 2008, November 2008.

[12] R. Q. Machado, S. Buso, J. A. Pomilio, “A LineInteractive Single-Phase to Three-Phase Converter System" IEEE Transaction on Power Electronics, vol. 21, No. 6, November 2006, pp. 1628-1636.

[13] R. Q. Machado, S. Buso, J. A. Pomilio, A. F. Q. Gonçalves, An Electronic Solution for the Direct Connection of a Three-phase Induction Generator to a Single-Phase Feeder, Controle \& Automação, vol. 20, no. 3, Jul.-Sept. 2009, pp. 417-426.

[14]E. G. Marra, J. A. Pomilio, Self-Excited Induction Generator Controlled by a VS-PWM Bi-directional Converter for Rural Application, IEEE Transaction on Industry Applications, vol. 35, No. 4, July/August 1999, pp. 877-883.

[15] Project IEEE-519, IEEE Recommended Practices and Requirements for Harmonic Control in Electric Power System, 1992.

[16] P. Mattavelli, Synchronous-Frame Harmonic Control for High-Performance AC Power Supplies, IEEE Transaction on Industry Applications, Vol. 37, No. 3, May/June 2001, pp. 864 - 872.

[17] R. Teodorescu, F. Blaabjerg, M. Liserre and P.C. Loh, "Proportional-resonant controllers and filters for gridconnected voltage-source converters”, IEE Proc.-Electr. 
Power Appl., Vol. 153, No. 5, September 2006, pp. 750762.

[18]P. C. Loh, M. J. Newman, D. N. Zmood, D. G. Holmes, A Comparative Analysis of Multiloop Voltage Regulation Strategies for Single and Three-Phase UPS Systems, IEEE Transaction on Power Electronics, Vol. 18, No. 5, September 2003, pp. 1176-1185.

[19] F.P. Marafão, S.M. Deckmann and E.K. Luna, A Novel Frequency and Positive Sequence Detector for Utility Applications and Power Quality Analysis, International Conference on Renewable Energy and Power Quality (ICREPQ), 2004.

[20]F. P. Marafão, S. M. Deckmann, J. A. Pomilio, R. Q. Machado, Metodologia de Projeto e Análise de Algoritmos de Sincronismo PLL, Eletrônica de Potência, Vol. 10-No.1, June 2005, pp. 7-14.

[21]C. B. Jacobina, E. C. dos Santos Jr., M. B. de R. Correa, E. R. C. da Silva, Sistema Distribuído de Geração Elétrica com um Gerador de Indução Trifásico Interligado com uma Rede Monofásica, Eletrônica de Potência, Vol. 11, no. 1, March 2006, pp. 43-51.

[22] M. S. Pádua, S. M. Deckmann, F. P. Marafão, A. Lopes, A. C. Moreira, Sincronismo de Sistemas de Geração Distribuída Baseado em Modelos Monofásico e Trifásico de Filtro de Kalman, Eletrônica de Potência, Vol. 12, no. 2, July 2007, pp. 105-112.

\section{BIOGRAPHIES}

Rodolfo Moreno Martínez was born in Lima, Perú. He received the Electrical Engineering Professional degree from Universidad Nacional de Ingenieria, Lima, Perú, in 1987, and in 1997 received the M.S. degree in Electrical Engineering from Universidade Estadual de Campinas, Campinas, São Paulo, Brazil where he is currently working toward the Ph.D. degree. Since 1986, he has been with Universidad Nacional de Ingenieria, Lima, Perú, as a Professor at the Department of Electrical Engineering working in the areas of electrical machines and power electronics. His research interests include electrical machine drives, FACTs devices and Distributed Generation System.

José Antenor Pomilio was born in Jundiaí, Brazil, in 1960. He received the Bachelor's (1983), the Master's (1986) and the Doctoral (1991) degrees in Electrical Engineering from the University of Campinas, Brazil. From 1988 to 1991 he was head of the Power Electronics Group at the Brazilian Synchrotron Laboratory. In 1993 and 2003 he was visiting professor at the University of Padova, and at the Third University of Rome, respectively. He is a Professor at the School of Electrical and Computer Engineering of the University of Campinas, where he teaches since 1984. He was president of the Brazilian Power Electronics Society (2000-2002), member of the Administrative Committee of the IEEE Power Electronics Society (1997-2002). He currently is associated editor of the IEEE Trans. on Power Electronics. His main interests are switching-mode power supplies, power factor correction, and active power filters.
Luiz C. P. da Silva was born in Brazil in 1972. He graduated in electrical engineering from the Federal University of Goiás, Brazil in 1995, and obtained MSc and $\mathrm{PhD}$ degrees in power systems engineering from the University of Campinas, Brazil, in 1997 and 2001 respectively. He worked as a visiting researcher at the University of Alberta, Canada, in 1999-2000, and as a guest professor at the Technical University of Denmark, in 2008. Since 2002 he is with the University of Campinas, Brazil, where he is an Associate Professor. His main areas of interest are power system voltage stability and control and distributed generation.

Sérgio Pires Pimentel was born in Goiânia, GO, Brazil in 1981. He received the B.S. degree in 2003 from Federal University of Goias, Goiania, Brazil, and the M.Sc. degree in 2006 from University of Campinas, Campinas, Brazil. Currently Mr. Pimentel is a Ph.D. student at the University of Campinas. Since 2009, he is also a professor at the Federal Institute of Education, Science and Technology of Goiás, Campus Itumbiara, Brazil. His research interests include control of power grid converters, active power filters, cascaded multilevel inverters, active islanding detection schemes and power quality. Mr. Pimentel is a student member of IEEE, SOBRAEP and SBA

\section{APPENDIX}

TABLE V

System Parameters

\begin{tabular}{clc}
\hline $\mathrm{V}_{\mathrm{dc}}$ & Dc-link voltage & $600 \mathrm{~V}$ \\
\hline $\mathrm{C}$ & Dc-link capacitor & $4700 \mathrm{uF}$ \\
\hline $\mathrm{L}_{\mathrm{f}}$ & Inverter filter inductor & $2.5 \mathrm{mH}$ \\
\hline $\mathrm{C}_{\mathrm{f}}$ & Inverter filter capacitor & $110 \mathrm{uF}$ \\
\hline $\mathrm{L}_{\mathrm{S}}$ & Coupling inductor of the interface with the grid & $1.5 \mathrm{mH}$ \\
\hline $\mathrm{V}_{\mathrm{b}}$ & Battery voltage & $300 \mathrm{~V}$ \\
\hline $\mathrm{L}_{\mathrm{b}}$ & Boost inductor & $1.0 \mathrm{mH}$ \\
\hline $\mathrm{R}_{\mathrm{Z}}$ & Buck resistance & $240 \mathrm{ohm}$ \\
\hline $\mathrm{Vs}$ & RMS line voltage of utility grid & $220 \mathrm{~V}$ \\
\hline $\mathrm{fs}$ & Frequency of voltage utility grid & $60 \mathrm{~Hz}$ \\
\hline $\mathrm{Zg}$ & Z-grid & $0.1 \mathrm{ohm}$ \\
\hline
\end{tabular}

TABLE VI

Induction Generator Parameters

\begin{tabular}{ll}
\hline Rate RMS phase voltage & $220 \mathrm{~V}$ \\
\hline Frequency & $60 \mathrm{~Hz}$ \\
\hline Power & $3 \mathrm{HP}$ \\
\hline Stator resistance & $0.435 \Omega$ \\
\hline Stator leakage inductance & $4.0 \mathrm{mH}$ \\
\hline Rotor resistance & $0.816 \Omega$ \\
\hline Rotor leakage inductance & $2.0 \mathrm{mH}$ \\
\hline Magnetizing inductance & $69.31 \mathrm{mH}$ \\
\hline Inertia & $0.05 \mathrm{~kg} \cdot \mathrm{m}^{2}$ \\
\hline No. of poles & 4 \\
\hline
\end{tabular}

TABLE VII

Three-phase rectifier

\begin{tabular}{ll}
\hline Active power & $2000 \mathrm{~W}$ \\
\hline Filter capacitor & $1200 \mathrm{uF}$ \\
\hline Load resistance & $41.0 \Omega$ \\
\hline
\end{tabular}

